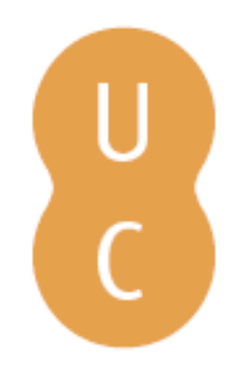

\title{
nombalina
}

\section{Democracia: as controvérsias de uma "maravilha" da historiografia herodotiana}

\author{
Autor(es): $\quad$ Soares, Carmen
}

Publicado por: Imprensa da Universidade de Coimbra

URL

persistente: URI:http://hdl.handle.net/10316.2/45145

DOI: $\quad$ DOI:https://doi.org/10.14195/978-989-26-1679-7_1

Accessed : $\quad$ 26-Apr-2023 10:57:50

A navegação consulta e descarregamento dos títulos inseridos nas Bibliotecas Digitais UC Digitalis, UC Pombalina e UC Impactum, pressupõem a aceitação plena e sem reservas dos Termos e Condições de Uso destas Bibliotecas Digitais, disponíveis em https://digitalis.uc.pt/pt-pt/termos.

Conforme exposto nos referidos Termos e Condições de Uso, o descarregamento de títulos de acesso restrito requer uma licença válida de autorização devendo o utilizador aceder ao(s) documento(s) a partir de um endereço de IP da instituição detentora da supramencionada licença.

Ao utilizador é apenas permitido o descarregamento para uso pessoal, pelo que o emprego do(s) título(s) descarregado(s) para outro fim, designadamente comercial, carece de autorização do respetivo autor ou editor da obra.

Na medida em que todas as obras da UC Digitalis se encontram protegidas pelo Código do Direito de Autor e Direitos Conexos e demais legislação aplicável, toda a cópia, parcial ou total, deste documento, nos casos em que é legalmente admitida, deverá conter ou fazer-se acompanhar por este aviso.

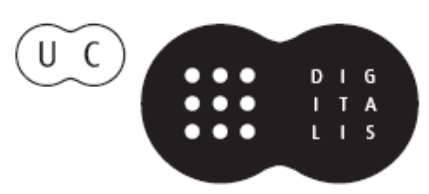



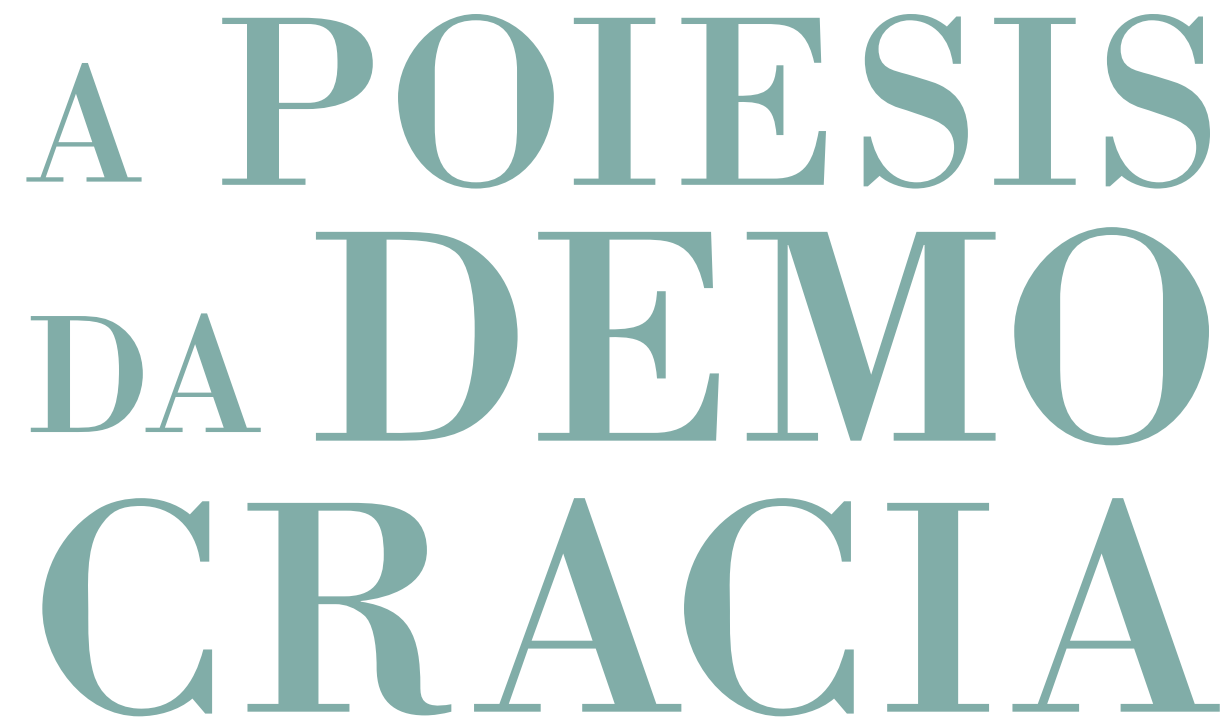

G

Breno Battistin Sebastiani, Delfim Leão,

Lugia Sano, Martinho Soares, Christian Werner

\section{CoimbraCompanions}




\title{
Democracia:
}

\author{
AS CONTROVÉRSIAS \\ DE UMA “MARAVILHA" DA \\ HISTORIOGRAFIA HERODOTIANA
}

DEMOCRACY :

CONTROVERSIES OF ONE OF

HERODOTUS' “WONDERS"

Carmen Soares

UNIVERSIDADE DE COIMBRA

ORCID | 0000-0003-3005-4635 


\section{Resumo}

A 'construção' (poiesis) da democracia na obra fundacional da historiografia ocidental, as Histórias de Heródoto, depende, antes demais, dos instrumentos de 'investigação' (bistoria) acionados pelo autor. Radica na aplicação de um método científico pautado por princípios como o espírito de isenção, a presença na narrativa herodotiana de construções diversas (favoráveis ou condenatórias) do regime popular. No ponto 1 deste estudo abordam-se as implicações dessa metodologia nas poieseis democráticas da fonte sob análise. É evidente desta abordagem que o tema não gera consensos entre as várias vozes da narrativa das Histórias, sendo o leitor confrontado com a 'maravilha' (thauma) da 'prática' (pragma) de uma democracia tirânica. A reflexão sobre essa construção híbrida e degenerada do governo popular desenvolve-se no ponto 2. Considerando o relevo do trecho conhecido por "Diálogo dos Persas" (3. 80-82) para a presente reflexão, apresenta-se em anexo a sua tradução integral para português.

\section{Palavras-chave}

Heródoto, democracia, historiografia, "Diálogo dos Persas" 


\section{Abstract}

The 'construction' (poiesis) of democracy in the foundational work of Western historiography, the Histories of Herodotus, depends first of all on the instruments of 'investigation' (bistoria) activated by the author. The presence in the Herodotean narrative of several constructions (favorable or condemnatory) of the popular regime is grounded in the application of a scientific method based on principles such as the spirit of exemption. In point 1 of this study are discussed the implications of this methodology in the democratic poieseis of the source under analysis. It is clear from this approach that the theme does not generate consensus among the various voices within the Histories narrative, and the reader is confronted with the 'wonder' (thauma) of the 'practice' (pragma) of a tyrannical democracy. The reflection on this hybrid and degenerated construction of popular government is developed in section 2. Considering the importance of the section known as "Debate of the Persian Grandees" (3. 80-82) for the present reflection, its full translation into Portuguese is also provided as an attachment to this study.

\section{Keywords}

Herodotus, democracy, historiography, "Debate of the Persian Grandees" 



\section{INTRODUÇÃO}

Há lugares comuns que, sem desprimor para a investigação científica assente na inovação, se impõem numa obra dedicado ao tema "A poiesis da democracia". O interesse de evocá-los reside tanto em perceber que essa popularidade resulta da sua condição de "clássico incontornável" como em explicar a atualidade de que continuam a revestir-se. Permitam-me que faça, desde já, um esclarecimento epistemológico: o conceito de atualidade aplico-o na dupla valência de conteúdo e método. Ou seja: o objeto de estudo é atual porque os temas em causa têm interesse para o tempo presente $^{1}$; a operatividade de metodologias de estudo contemporâneas, aplicadas a esse objeto de estudo, torna-o atual.

O "clássico incontornável" a que me reporto neste estudo é o discurso político nas Histórias de Heródoto. E, embora o foco de pesquisa afunile para uma forma de governação em particular (a democracia), veremos que, no pensamento do historiador, as conceções e as práticas (ou, se preferirmos vocábulos gregos, a theoria e a praxis) que definem o regime democrático terão sempre de ser equacionadas na sua relação com as formas de governo em que a soberania não assiste à multidão (a tirania, a monarquia e a oligarquia). A investigação que, há vários anos, tenho vindo a desenvolver sobre estas matérias conduziu à identificação de mais duas perspetivas de análise, indispensáveis, a meu ver, para se produzir uma leitura atual, numa

1 Não se defende, com isto, uma continuidade entre a Antiguidade e a modernidade, processo segundo o qual os problemas (perenes na história da humanidade) e conceitos apenas evoluiriam, mas sim uma história contextualizada. Sobre a pertinência de se proceder ao estudo da história do pensamento político sob esta perspetiva, leia-se Wagner (2013: 4749). 
obra que foi composta à volta do último quartel do séc. V a.C., dos regimes políticos em geral e da democracia em particular ${ }^{2}$.

A articulação entre essas duas linhas de leitura permitirá aproximarmo-nos do desígnio maior deste estudo: uma leitura holística do topos da democracia nas Histórias. Passarei a enunciar, sumariamente, cada uma delas, bem como a avançar com os resultados a que me conduziram, pelo que se dispensa uma rubrica final neste estudo para "conclusões".

1. Discurso historiográfico, o método científico aplicado à narrativa do passado: o alinhamento da 'investigação' (bistoria) de Heródoto com a metodologia de cientistas seus antecessores e contemporâneos - nos domínios da medicina, das ciências da terra e das ciências da vida - é essencial para se compreender a 'construção' (poiesis) da democracia nas Históriasª . Ao proceder-se à aplicação da grelha do método científico, ou seja de um método de produção de conhecimento, à escrita herodotiana conclui-se que o "espírito de isenção" do historiador, evidenciado na coexistência no seu texto tanto de narrativas favoráveis como pejorativas sobre o regime democrático, deriva da própria "cientificidade" do discurso historiográfico.

2. As "maravilhas", um objeto da narrativa historiográfica: a democracia tirânica. O enfoque em assuntos que, pelo seu caráter extraordinário e afastamento em relação ao quotidiano conhecido, causam espanto e cativam o interesse do público das Histórias condiciona a seleção da matéria e o tratamento que lhe é dado pelo historiador; a aposta de Heródoto em acentuar as semelhanças do regime democrático com aquele que, pelo número de governantes, se afiguraria seu natural oposto (a tirania), deriva, a meu ver, também do desígnio programático do autor de "maravilhar" (surpreendendo) os destinatários da obra.

2 Para outras abordagens sobre o pensamento político em geral no texto herodotiano, vd.: Romilly 1959, Lasserre 1976, Evans 1981, Lateiner 1984, Rocha Pereira 1981 e 1990 , Pelling 2002. Relativamente à reflexão sobre a democracia na obra, veja-se Moles 2002 (para o caso concreto da democracia ateniense) e Grethlein 2013 (que aborda a questão sob o prisma do uso da oratória, mecanismo essencial ao exercício do governo popular).

3 Como bem observou Thomas (2006), algumas das figuras e obras de cujo discurso científico se aproxima Heródoto são os escritos dos médicos do Corpus Hippocraticum, de filósofos naturalistas, de poetas racionalistas (como Xenófanes) e mesmo de sofistas. Entre as temáticas que os unem encontram-se as relações entre physis e nomos, em particular a teoria do determinismo geográfico e climatérico do modo de vida (diaita) dos povos. 
Estruturei a minha proposta de reflexão com base nestas duas perspetivas de análise, que passo a desenvolver de forma detalhada, dando a conhecer o raciocínio que levou às conclusões acabadas de apresentar.

\section{Discurso historiográfico: o método Científico aplicado À NARRATIVA DO PASSADO}

Como bem demonstrou Rosalind Thomas (2000, 2006), a prosa herodotiana comporta muitos marcadores do "discurso científico" vigente em escritos contemporâneos do autor ou muito recentes, da autoria de médicos e de filósofos naturalistas, oriundos, como Heródoto, da Iónia. Os corpora de textos sobreviventes confirmam como a nova corrente de pesquisa científica, isto é, de alcance de conhecimento, se distancia da herança dos filósofos pré-socráticos iónios do séc. VI a.C. Na verdade, os alicerces do pensamento científico deixaram de ser as especulações "invisíveis" e o abstrato, substituídos pelo estudo do tangível, do visível e do empiricamente verificável ${ }^{4}$.

Paradigmático, em matéria de alicerces fundadores do edifício que é o conhecimento histórico, é o cap. 99 do Livro II das Histórias. Quando

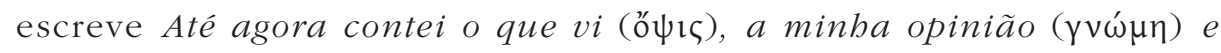

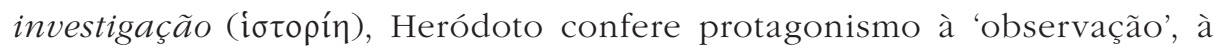
capacidade de formular um 'juízo' próprio, ou seja de fazer a crítica das fontes, atividades entendidas como complementares da 'investigação'. Assim, a opsis, a gnome e a historie definem os contornos do método científico adotado por Heródoto, que tem por principais marcadores discursivos a referência às fontes consultadas (orais ou escritas), a análise crítica dessas fontes (que se traduz nos comentários pessoais do historiador), o relevo dado aos testemunhos diretos (colhidos pela 'observação do próprio': gr. autopsia) e aos indiretos (ouvidos da boca de terceiros: gr. akoe), bem como à autonomia especulativa. A propósito dos testemunhos orais, relatados e atribuídos a outros (identificados ou anónimos), convém desde já clarificar

4 Cf. Thomas 2006: 62. 
que, como bem expôs Nino Luraghi5, eles são um mecanismo de distanciamento do autor em relação à situação apresentada. Este distanciamento serve para tornar o seu discurso mais objetivo, já que radica na autoridade que uma tradição oral (à época ainda de grande valor para um público mais familiarizado com a oralidade do que com a escrita). Em suma, o papel do historiador não é narrar verdades (embora possa revelar a sua credulidade ou incredulidade), mas histórias, cabendo em última instância ao seu leitor acreditar nelas ou não ${ }^{6}$. Como argumenta o referido helenista ${ }^{7}$, a historiografia antiga é um "complexo artefacto cultural" e não uma reflexão sobre "factos verdadeiros" extra-textuais ${ }^{8}$.

O que a historie deve fazer é explicar, tornando claro ou revelandoํ, o que estava obscuro ou se desconhecia, ou seja, afastar-se do 'invisível' e 'intangível', para se centrar no verificável. Há que fazer um esclarecimento importante quanto ao que se entende por verificável, já que ultrapassa o domínio da realidade factual para incluir também o raciocínio lógico. Quer isto dizer que o cientista não produz conhecimento apenas empírico, mas também especulativo. Exemplar a esse respeito é o passo que se segue, no qual o historiador refuta ser o degelo das neves responsável pelas cheias do Nilo durante o verão (2. 22. 2):

A um indivíduo que tenha a capacidade de raciocinar ( $\lambda$ oүí $\zeta \varepsilon \sigma \theta \alpha$ ) sobre estes aspetos a primeira e mais poderosa prova ( $\mu \alpha \rho \tau$ úpıov) de não ser nada verosímil que o Nilo nasça da neve oferecem-na os ventos, ao soprarem quentes, a partir dessas mesmas regiões.

No entanto, a humildade científica, ou seja, a consciência dos limites do conhecimento humano, serve de moderadora ao impulso do investigador

5 Luraghi 2007: 80-83.

6 Essa é a ilação retirada ainda por Luraghi (2007: 87).

7 Luraghi 2007: 88.

8 Sobre o género literário das Histórias, vd. Boedeker 2000 e 2002.

9 Essa função "reveladora" da investigação está bem evidente na terminologia do passo

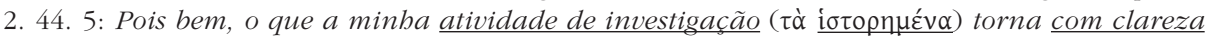
evidente $(\delta \eta \lambda$ ĩ $\sigma \alpha \varphi \underline{\varepsilon} \omega \varsigma)$ é que Héracles é um deus antigo. Todas as traduções apresentadas são da minha autoria. 
para produzir verdades absolutas. Dessa mesma realidade nos dá conta Heródoto, no contexto do quadro de averiguação sobre a difusão do culto do deus e herói Héracles, ao esclarecer (2. 44. 1):

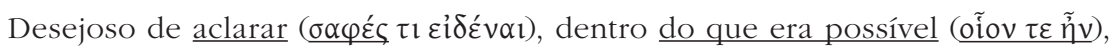
um pouco esta questão, naveguei mesmo até Tiro na Fenícia, depois de me informar que aí havia um templo consagrado a Héracles.

Vejamos, agora, como as metodologias da investigação (a chamada meta-bistorie ${ }^{10}$ ) perpassam em trechos de reflexão teórica e prática sobre a governação democrática, condicionando a poiesis do regime no texto de Heródoto. Começaremos pelo famoso passo fundador do pensamento político ocidental (3. 80-82), a que se seguem quadros mais breves de reflexão e prática democráticas.

O conhecido "Diálogo dos Persas", que já tive ocasião de analisar sob outras perspetivas ${ }^{11}$, é um caso de akoe anónima. Heródoto não identifica a origem da sua fonte, que só pode ser indireta, já que situa os acontecimentos num passado que não vivenciou, a conjura persa para depor o Medo Gaumata (522 a.C.). O que numa primeira leitura do passo sobressai é a posição de narrador isento de 'juízos' (gnomai), os quais vêm exclusivamente atribuídos às personagens envolvidas. A insistência do autor em que está a transmitir as gnomai de terceiros é passível de várias interpretações, não excludentes entre si $^{12}$. Além de revelar isenção e objetividade, premissas do discurso científico em geral, o recurso à akoe serve para conferir autoridade ao narrado.

O que pode parecer um contrassenso à luz da historiografia moderna (recorrer à tradição oral, e não à escrita, para legitimar o discurso histórico) corresponde à realidade do tempo de Heródoto. Como argumentou Nino Luraghi (2007: 80-83), Heródoto escreve, mas não deixa por isso de ser um

10 Expressão proposta por Luraghi (2007), pelo sentido literal que encerra de 'auxiliar' (gr. meta) da 'investigação' (gr. historie).

11 Soares 2014a, 2014b, 2016.

12 O substantivo gnome vem sete vezes usado: 80. 6; 81. 1 (bis); 82. 1 (bis); 82. 5; 83. 1. 
"historiador oral", o que se nota na própria metodologia da investigação histórica praticada, que apresenta uma diminuta abonação através de obras e autores, por contraste com uma insistente referência a fontes orais coletivas. Num momento em que o género historiográfico ainda se estava a afirmar, era natural a sobrevivência de práticas herdadas, tanto mais que o público "confiava" sobretudo na tradição (transmitida oralmente desde tempos imemoriáveis) e não tanto nas (recentes) obras escritas. Por essa razão é que a akoe constitui um recurso da metodologia da 'investigação' (bistorie) capaz de conferir autoridade ao narrado.

Retomando o texto introdutório do diálogo dos Persas, em que Heródoto afirma foram proferidos discursos inacreditáveis (na opinião de alguns Gregos), mas a verdade é que foram proferidos (3. 80. 1), percebemos que o historiador não emite opinião sobre a autenticidade ou não do conteúdo das falas, apesar de ter consciência de que essa é uma questão polémica. Quanto a este esclarecimento introdutório de Heródoto ao debate político que apresenta, importa compreendê-lo à luz da linha de leitura que desenvolverei no ponto 2 desta análise. Ou seja, nesta denúncia declarada do autor quanto à dimensão fraturante do episódio (para uns verdadeiro, para outros falso) reside o carácter "maravilhoso" do episódio, o qual justifica a sua inclusão nas Histórias. Conforme abordarei adiante, é por serem "surpreendentes" que essas falas dos nobres persas em matéria de reflexão política se enquadram na narrativa histórica herodotiana.

Ou seja, no seu mais extenso passo sobre teorização política, Heródoto faz crer ao leitor que assume o papel de transmissor de uma tradição que lhe chega por via indeterminada. O mesmo é dizer que os recursos metodológicos evidenciados revelam que a poiesis da democracia, presente nesse passo, pode ser considerada a visão tradicional de meados do séc. V a.C. No diálogo cada um dos aristocratas persas argumenta a favor da forma de governação que considerava ser a melhor, excelência que sobressai do contraste com as poieseis de outros regimes. Enquanto Otanes (3. 80) exalta o governo da maioria e condena a forma degenerada do governo de um só (a monarchia que tem por líder o tyrannos); Megabizo (3. 81) ataca em particular a governação popular, agora retratada como vil (kakos), propondo como melhor regime a oligarquia (ou, como se lhe refere, uma 'assembleia 


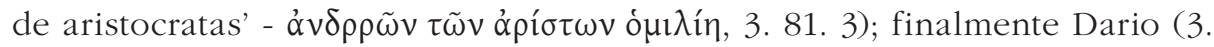
82) descreve as 'más' (kakoi) formas dos governos oligárquico e popular, todas opostas, na sua 'degeneração' (kakotes), ao governo de um só, a monarquia esclarecida, assegurada pelo monarca 'excelente' (aristos).

$\mathrm{Na}$ maioria dos restantes passos em que se caracterizam as politeiai (termo ausente do texto herodotiano), o historiador continua a preferir o recurso ao discurso direto, atribuindo a personagens da narração a autoria dessas poieseis. Assim sucede nos livros 3, 5 e 7, nos trechos em que dá conta das "conversões" dos tiranos gregos Meândrio (de Samos: 3. 142), Aristágoras (de Mileto: 5. 37) e Cadmo (de Cós: 7. 164) em democratas. Todos estes passos serão retomados no ponto 2 da minha análise.

Porém, quando é Heródoto que, na sua voz autoral de narrador, assume o papel de construtor do retrato da democracia, deparamos com uma poiesis positiva do regime. É o que sucede em 5. 78, onde dá conta do contributo decisivo da igualdade de direitos políticos para o aumento da motivação dos guerreiros. A propósito da retaliação dos Atenienses contra Beócios e Calcidenses, por terem sido aliados dos Espartanos, em finais do séc. VI, nos ataques à cidade de Palas Atena, comenta Heródoto:

Foi nessa altura que os Atenienses começaram a ganhar poder. É evidente - não por uma só razão, mas por muitas - que a igualdade de expressão (ionүopín) é um bem apreciado ( $\chi \rho \tilde{\eta} \mu \alpha \sigma \pi o v \delta \alpha i ̃ o v)$, visto que os Atenienses, quando viviam na tirania, em combate não eram em nada melhores do que os seus vizinhos, mas, depois de se terem livrado dos tiranos, tornaram-se de longe os primeiros. O que, sem dúvida, isto evidencia é que, quando subjugados, se faziam passar por cobardes, porque estavam ao serviço de um tirano, mas que, depois de libertados, cada um desejava vivamente atingir os seus objetivos pessoais.

Há, no entanto, que ressalvar que o elogio da democracia neste passo figura num contexto muito preciso, o de condenação do governo tirânico.

Podemos, desde já, tirar uma conclusão deste exercício de comparação entre o uso da akoe e da gnome do autor para caracterizar a democracia: ambas as metodologias concorrem para a ideia de que a poiesis do regime 
assenta no confronto com outras formas de governação, muito em particular com aquela que, pelo número de governantes, se situa no extremo oposto, a tirania.

\section{As "MARAVilhas", Um ObJETO dA NARRATiVA historiográfica: A DEMOCRACIA TIRÂNICA}

O prólogo tem para o leitor-ouvinte das Histórias o interesse de fornecer uma chave de leitura quanto às temáticas privilegiadas e objetivos da obra. Recordemos essas palavras:

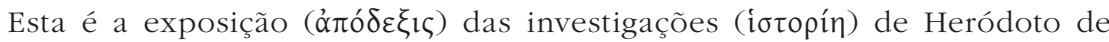
Halicarnasso, para que, com o tempo, nem os feitos dos homens se apaguem, nem fiquem privadas de renome as empresas ( $\left.\varepsilon^{\prime} p \gamma \alpha\right)$ grandes e maravilhosas $(\theta \omega \cup \mu \alpha \sigma \tau \alpha ́)$, cometidas tanto por Gregos como por Bárbaros, e, acima de tudo, a razão ( $\alpha i$ íín) por que combateram uns contra os outros.

Centremo-nos na tónica colocada no relato de "empresas maravilhosas" ( $\varepsilon_{\rho}^{p} \gamma \alpha \theta \omega u \mu \alpha \sigma \tau \alpha$ ). A mais comum aceção do adjetivo remete para 'admirável, surpreendente, espantoso, prodigioso' e associa-se a aspetos da natureza (terra e animais) e do sobrenatural. Mas o que uma narrativa cheia de peripécias como é a historie herodotiana demonstra é que o autor seguramente espanta e provoca a admiração do seu público também pelo tratamento dado a questões que, fazendo parte do quotidiano, suscitavam opiniões contraditórias. Como já bem observou Christopher Pelling (2002), o debate político dos Persas reflete com grande probabilidade opiniões que circulariam nos meios cultos contemporâneos de Heródoto ${ }^{13}$. Ou seja, a surpresa que esse diálogo causaria reside não tanto nos retratos dos regimes, mas, uma

13 Munson (2013), por seu turno, advoga haver mais influência persa nessa discussão do que se tem pensado. O próprio facto de Heródoto referir por duas vezes (3. 80. 1 e 6. 43. 3) que os Persas deliberaram sobre o seu futuro político após a morte de Cambises é pela helenista considerado (idem: 326, n. 21) uma evidência de que o historiador se apoiaria numa tradição persa para a construção do Diálogo dos Persas. 
vez mais, na estratégia discursiva adotada. Esta consiste em escrever a história contemporânea no subtexto da história do passado, arte em que Heródoto foi mestre, como já sublinharam John Moles (2002: 50) e Philip Stadter (2006).

Assim, o público das Histórias, familiarizado com o imperialismo ateniense (cimentado no pós-Guerras Medo-persas e responsável pelo estalar da Guerra do Peloponeso), admiraria a subtileza discursiva do prosador, que, sem lhe dar um título próprio, constrói da democracia uma versão tirânica. Diríamos, mesmo, que a poiesis herodotiana do governo degenerado da democracia constitui um prenúncio da Atenas tyrannis da História do Peloponeso de Tucídides ${ }^{14}$.

Para que melhor se compreenda que a 'construção' (poiesis) de uma democracia tirânica por Heródoto corresponde a uma das várias "empresas maravilhosas" da sua narrativa, devemos ter presente que o historiador, no episódio emblemático do Diálogo dos Persas sobre a melhor 'prática governativa' (daí o uso do substantivo pragma, da família do verbo 'agir, atuar', prassein, e não de politeia), desmonta a tradicional conceção de três regimes distintos. É essa tripartição convencional que Dario evoca na sua fala (3. 82. 1):

Dos três regimes que temos à nossa disposição, afirmo que - apesar de todos eles serem os melhores (é o melhor o governo do povo, a oligarquia e a monarquia) - este último é de longe superior aos outros.

Da leitura completa do debate constitucional, cuja tradução apresentamos em anexo, torna-se claro que, ao colocar na boca das suas personagens, para cada uma das constituições tradicionais, uma versão 'boa' (considerada 'melhor', i.e., aristos) e outra 'má' (apelidada de 'vil', i.e., kakos), Heródoto complexifica o sistema convencional de três regimes, cujo principal fator de distinção era o número de governantes: um só (monarquia), poucos (oligarquia) e a multidão (democracia). Como já defendi noutro lugar (Soares 2016), embora o historiador apenas mencione nomes distintos para quatro

14 Cf. uso desse substantivo em 2. 63. 2 e 3. 37. 2. 
formas de governo - isonomia, oligarquia, monarquia e tirania - a verdade é que permite ao recetor da sua obra distinguir claramente seis pragmata distintos.

Ao regime popular bem ordenado, pautado pela partilha igual da governação, dá o seu defensor no diálogo, Otanes, uma designação de etimologia francamente positiva: isonomie (forma iónica, a que corresponde o ático isonomia). Na sua composição entram o adjetivo e o substantivo que encerram o essencial desta forma de regime, a saber: os governantes possuírem uma 'parte' (nomos) 'igual' (isos) no governo da polis. Será na boca dos seus opositores (Megabizo e Dario) que deparamos, não com o termo já em voga (demokratia) ${ }^{15}$, mas com o emprego do substantivo 'povo' (demos), então negativamente conotado nos meios aristocráticos, que lhe associavam a origem humilde e, consequentemente, pouco esclarecida e influenciável das gentes do povo. Ou seja, estamos perante a divisão da mesma constituição (politeia) em duas formas de governo, isto é, duas "práticas governativas" (daí Heródoto chamar-lhes pragmata) - a isonomia e o 'poder (kratos, arkhein) da multidão (plethos) ou povo (demos)' (como se lhe referem Megabizo e Dario).

À governação oligárquica de que fala Megabizo, pautada pela excelência dos seus governantes, opõe-se a prática descrita por Dario, caracterizada por disputas entre pares (aristocratas) por lideranças individuais. Ou seja, embora Heródoto não use dois termos diversos para distinguir uma forma de governação da outra, na verdade estamos perante nova divisão de uma mesma politeia (a oligarquia) em dois pragmata, um 'melhor' (aristos) e outro 'degenerado', já que leva ao aparecimento, entre os oligarcas, de

15 Repare-se que, embora Heródoto use tanto este substantivo como o verbo demokrateesthai noutros passos das suas Histórias (respetivamente: 6. 43. 3 e 131. 1; 4.137. 2 e 6. 43. 3), parece evitá-lo no passo de teorização política que compôs. A meu ver, podemos avançar com duas hipotéticas explicações para, nestes passos, o historiador não ter hesitado em usar ambos os termos: o sentido neutro (despido de conotação negativa) que acabou por adquirir (e que vem consagrado por Platão, no seu Político 292a: No respeitante à democracia, quer as massas exerçam o poder sobre os detentores da riqueza pela força ou livremente, quer respeitem escrupulosamente ou não as leis, não há, em absoluto, o hábito de lbe mudar o nome); não haver, nestes passos, destinatários internos do discurso a quem é necessário convencer da 'boa' atuação dos governos populares, pelo que não se recorre ao termo positivo isonomia e se emprega o genérico demokratia. 
rivalidades insanáveis, das quais nascem dissensões, das dissensões bomicídios (3. 82. 3).

Não obstante o Diálogo dos Persas poder ser entendido como um claro esforço de Heródoto para distinguir seis formas de atuação governativa, a verdade é que, como acabámos de ver, este trecho não só "maravilha" o seu ouvinte-leitor por desdobrar cada politeia em duas poieseis distintas, originando seis pragmata políticos, mas também por, no que ao regime popular (objeto deste estudo) diz respeito, revelar como, na sua forma degenerada (em que prevalece a 'vilania', a kakotes mencionada por Dario, 3. 82. 4), ele se identifica com características essenciais de outra prática governativa, a tirania. Passaremos, de seguida, em revista os momentos discursivos das Histórias que permitem ao seu recetor distinguir uma poiesis pró-democrata de uma poiesis anti-democrata do regime popular.

Fundamental para a interpretação que esses passos possibilitam em termos de história das mentalidades é a perceção de quem são os seus emissores intradiegéticos. Há que distinguir as afirmações e comentários atribuíveis ao historiador daqueles que ele coloca na boca das suas personagens. Comecemos pelas poieseis favoráveis do regime democrático. $\mathrm{Na}$ boca de quem as coloca Heródoto e em que contextos políticos? $\mathrm{Na}$ boca de aristocratas, em momentos de rutura política. Como podemos interpretar esses posicionamentos pró-democratas? Qualquer tentativa de resposta a este questionário exige um comentário mais detalhado dos contextos de ocorrência, o que faremos de seguida, pela ordem em que surgem na obra.

No Diálogo dos Persas, cabe a um nobre assumir-se como porta-voz da melhor forma de governo popular, a isonomia. Tão importante é perceber quais são as práticas que a tornam uma governação exemplar, como o contexto político em que Heródoto coloca um aristocrata a fazer semelhante elogio. Comecemos por este aspeto, no geral desvalorizado. A circunstância é a de um golpe de estado, levado a cabo por sete conjurados persas. Ou seja, num momento de crise, a mudança de regime (com a substituição do anterior modelo monárquico por uma democracia) afigura-se ao proponente da proposta de reviravolta política a alternativa que viabilizaria assegurar o estatuto privilegiado que detinha e que estaria eventualmente em risco. 
Prova disso é que, ao ver derrotada a sua proposta de instituir na Pérsia a governação popular - regime que implicava o estabelecimento da igualdade (isotes) entre todos, contrariando a hierarquização que uma monarquia estabelecia entre a família real e os restantes súbditos (mesmo os nobres) - Otanes reivindica para si e seus descendentes um tratamento de exceção, baseado na isotes característica da democracia. As razões pessoais que fizeram de Otanes um pró-democrata vêm confirmadas por Heródoto no final do passo 3. 83. 3:

Ainda hoje esta é a única família persa a permanecer livre e a ser governada só naquilo que ela própria quiser, desde que não infrinja as normas dos Persas.

Repare-se que Heródoto não emprega o substantivo isotes, mas consubstancia essa ideia através de uma expressão preposicional com o sentido de '[colocar o poder] no meio [de todos]' (es meson). Otanes, caracterizando a essência da isonomia, deixava implícito nessa construção que os pragmata eram colocados a uma distância/proximidade igual de todos (daí a tradução que proponho para 3. 80. 2: 'defendia que a governação fosse entregue aos Persas de forma equitativa'). Também nos modi operandi identificados como próprios da prática governativa isónoma fica implícito o princípio da igualdade: o acesso aos cargos por tiragem à sorte, a prestação de contas em relação ao uso de fundos públicos e a tomada de decisões em comum (3. 80. 6).

Voltamos a reencontrar idênticas poieseis favoráveis da democracia mais adiante nas Histórias, a propósito de verdadeiras "operações de charme" de tiranos gregos junto das populações de cidades onde o regime entrara em crise. Uma vez mais, cabe a aristocratas que pretendem assegurar interesses pessoais (que passam por um estatuto social, económico e político elevado) assumirem-se como (falsos) paladinos do principal alicerce da isonomia, a igualdade. Assim sucede com Meândrio de Samos (3. 142), Aristágoras de Mileto (5. 37) e Cadmo de Cós (7.164). Todos eles "fingem" abdicar da tirania, substituindo-a por regimes assentes na "igual (isos) parte (nomos)". É interessante notar que a própria seleção vocabular que nesses 
três novos passos o historiador emprega para dar conta dos propósitos democráticos dos políticos em questão é coerente com o ensaio teórico do Diálogo dos Persas. Efetivamente, Heródoto retoma as expressões da fala de Otanes que denunciam a centralidade do princípio da igualdade no regime democrático: es meson e isonomia.

Tanto no logos de Meândrio como no de Aristágoras, é possível detetar indícios de que será intencional o uso do nome de sentido favorável, isonomia, em vez do termo pejorativo, "democracia". Exilado e morto o tirano de Samos, Polícrates, Meândrio procurou conquistar a simpatia dos seus conterrâneos apresentando-se como paladino da liberdade e da justiça. Anunciou, para tal, a sua renúncia ao poder tirânico. Os termos em que faz o anúncio da substituição de um regime pelo outro ecoam a poiesis da governação da multidão tal qual a descreveu Otanes, conforme se percebe do passo 3.142. 3: 'colocando no meio de vós o poder, anuncio-vos a

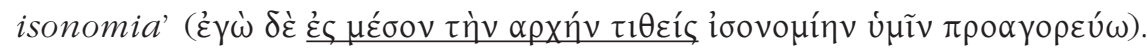

Também o retrato que Heródoto nos dá da praxis de Aristágoras revela que a democracia não passa de uma escolha política oportunista. O seu desígnio íntimo, para mudar de regime (rebelando-se contra o domínio persa, conotado com o exercício da tirania em Mileto), era continuar ligado ao poder (na forma de governação que poderia gerar mais consenso entre a população, de cujo apoio necessitava). Desse oportunismo político nos dá conta Heródoto ao comentar (5. 37. 2):

Em primeiro lugar renunciou verbalmente à tirania e instaurou em Mileto a isonomia, a fim de, tendo os Milésios do seu lado, convocá-los ao seu intuito de revolta.

Num contexto geral de insurreição de muitas poleis vizinhas contra os tiranos no governo, apoiados pelo rei persa, o regente de Histieu percebeu que a maneira de não acabar expulso ou morto consistiria em tomar a iniciativa de liderar uma substituição de regime, ganhando a simpatia dos conterrâneos e das comunidades gregas próximas.

Mas é a forma degenerada da governação das massas que permite ao historiador construir a "maravilha" que é a democracia tirânica. Não lhe 
atribui esta designação, que como vimos atrás caberá a Tucídides verbalizar, mas permite ao seu leitor-ouvinte perceber os traços essenciais dessa 'construção' (poiesis) despótica do regime popular. Retomemos o Diálogo dos Persas, mais concretamente as falas de Megabizo e Dario, pois elas encerram a identificação dos três pontos em comum entre os pragmata do tirano e do povo. São eles a 'insolência, imoderação ou excessos' (contidas no substantivo bybris) - que em linguagem atual, aplicada ao contexto político, traduziríamos por 'abusos de poder' - as decisões erradas e a sobreposição dos interesses individuais aos de um coletivo ou grupo.

Tal como Otanes denunciara ser a bybris um predicado do bomem que é tirano (andra ge tyrannon, 3. 80. 4), i.e., produto do poder concentrado num único governante, Megabizo aponta ao povo a mesma pecha, deixando claro que os dois regimes podem coincidir na mesma prática (3. 81. 2):

Sem dúvida é absolutamente intolerável que homens que fogem da insolência (bybris) de um tirano venham a cair na insolência (bybris) de um povo indisciplinado.

Os juízos errados são aqueles que, em vez de se pautarem pelo 'belo' (kalos) ou 'melhor' (aristos), redundam em atos ou manifestações de 'vilania' ou, como lhe chamaríamos modernamente, de 'mau carácter' (kakotes). Otanes destaca esse comportamento como típico do tirano (3. 30. 4). Dario retoma-o, quando critica as cumplicidades (as 'alianças', philiai, referidas em 3.82. 4) que se estabelecem entre os governantes oriundos do povo e que servem para se desculparem mutuamente das decisões erradas ('os atos de vilania'):

Quando o povo governa, é inevitável o aparecimento da vilania! E quando a vilania se orienta para o interesse comum, o que surge entre os vilões não são rivalidades, mas sim poderosas alianças! A verdade é que os que cometem atos de vilania contra o interesse comum se encobrem mutuamente. 
Repare-se que essas decisões erradas são tomadas 'contra o interesse comum' (es ta koina), donde é legítimo deduzir que, mesmo numa democracia, há casos em que os interesses individuais são colocados acima do 'interesse comum'. Caso paradigmático apresentado nas Histórias é o do general ateniense Temístocles ${ }^{16}$, democrata que os Eubeus "compram" por 30 talentos, valor pelo qual aceita convencer os aliados navais gregos a permanecerem na zona do cabo Artemísio, defendendo assim a ilha Eubeia de um provável ataque do invasor persa.

\section{BIBLIOGRAFIA}

Boedeker, D. (2000), "Herodotus' Genre(s)", in M. Depew, D. Obbink (eds.), Matrices, Canons and Society. Cambridge, 97-114.

Boedeker, D. (2002), "Epic Heritage and Mythical Patterns in Herodotus", in E. Bakker, I. J. F. de Jong, H. van Wees (eds.), Brill's Companion to Herodotus. Leiden, Boston, Cologne, 97-116.

Cartledge, P. (2009), Ancient Greek Political Thought in Practice. Cambridge.

Evans, J. A. S. (1981), "Notes on the Debate of the Persian Grandees in Herodotus 3, 80-82", QUCC 36: $79-84$

Grethlein, J. (2013), "Democracy, Oratory, and the Rise of Historiography in Fifth-century", in J. P. Arnason, K. A. Raaflaub, P. Wagner (eds.), The Greek polis and the Invention of Democracy. Malden, 126-143.

Lasserre, F. (1976), "Hérodote et Protagoras: le débat sur les constitutions", MH 33: 65-84.

Lateiner, D. (1984), "Herodotean Historiographical Patterning: the Constitutional Debate", QS 20: 257-284.

Luraghi, N. (2006), "Meta-historie: Method and Genre in the Histories", in Dewald, C. , Marincola, J. (eds.), The Cambridge Companion to Herodotus. Cambridge, 76-91.

Moles, J. (2002), "Herodotus and Athens", in E. J. Bakker, I. J. F. de Jong, H. van Wees (eds.), Brill's Companion to Herodotus. Leiden, Boston, Köln, 33-52.

Munson, R. V. (2013), "Who are Herodotus' Persians?", in R. V. Munson (ed.), Herodotus: Volume 2. Herodotus and the World. Oxford, 321-335.

Pelling, Ch. (2002), "Speech and Action: Herodotus' Debate on the Constitutions", PCPhS 48: 123158.

Rocha Pereira, M. H. (1981), "O mais antigo texto europeu de teoria política", Nova Renascença 1: 364-370.

Rocha Pereira, M. H. (1990), "O ‘Diálogo dos Persas' em Heródoto", Estudos Portugueses. Homenagem a António José Saraiva. Lisboa: 351-362.

Romilly, J. (1959), "Le classement des constitutions d' Hérodote à Aristote", REG 72: 81-99.

16 Estadista que já retratei como um verdadeiro "político dos mil artifícios" (Soares 2002: 33). 
Romm, J. (2006), "Herodotus and the Natural World", C. Dewald, J. Marincola (eds.), The Cambridge Companion to Herodotus. Cambridge University Press, 178-191.

Stadter, Ph. (2006), "Herodotus and the Cities of Mainland Greece", in C. Dewald, J. Marincola (eds.), The Cambridge Companion to Herodotus. Cambridge, 242-256.

Soares, C. (2002), "Introdução", in J. R. Ferreira, C. Soares, Heródoto. Histórias $8^{\circ}$. Introdução, versão do grego e notas, Lisboa, 11-33.

Soares, C. (2014a), "Theoria e práxis política em Heródoto", Cuadernos de Filología Clássica: Estudios griegos e indoeuropeus 24: 57-79.

Soares, C. (2014b), "Diálogos nas Histórias de Heródoto entre teoria e praxis política. Tirania e democracia: contrastes e semelhanças", Phoînix: 25-39.

Soares, C. (2016), "Regimes políticos nas Histórias de Heródoto: o "Diálogo dos Persas" (3. 80-82)", in C. Soares, M. C. Fialho, Th. Figueira (eds.), Polis/Cosmópolis: identidades globais \& locais. Coimbra, 43-52.

Thomas, R. (2000), Herodotus in Context: Ethnography, Science and the Art of Persuasion. Oxford.

Thomas, R. (2006), "The Intellectual Milieu of Herodotus", in C. Dewald and J. Marincola (eds.), The Cambridge Companion to Herodotus. Cambridge, 60-75.

Wagner, P. (2013), "Transformations of Democracy: Towards a History of Political Thought and Practice in Long-term Perspective", in J. P. Arnason, K. A. Raaflaub, P. Wagner (eds.), The Greek polis and the Invention of Democracy. Malden, 47-68.

\section{ANEXO}

\section{Histórias 3. 80-82 ${ }^{17}$}

80. 1. Depois que terminou a agitação e que passaram cinco dias, os que se tinham sublevado contra os Magos discutiram sobre todas as formas de governação ${ }^{18}$ e foram proferidos discursos inacreditáveis (na opinião de alguns Gregos), mas a verdade é que foram proferidos. 2. Otanes defendia que a governação fosse entregue aos Persas de forma equitativa19, argumentando o seguinte: "Sou do parecer que não mais um de nós se torne monarca! De facto, essa situação não é agradável, nem boa. Bem vistes não só a que ponto chegou a insolência de Cambises, como também

17 Publicado originalmente em Soares 2014b: 33-35.

18 A forma de plural do substantivo neutro $\pi \rho \eta ́ \gamma \mu \alpha \tau \alpha$, aqui usada, tem um sentido derivado dos valores denotativos 'feitos, negócios' (públicos, por oposição a privados), a saber 'governação'. Cartledge (2009: 4) explica este sentido genérico, que, no caso da língua portuguesa, em contextos mais específicos, como é o do texto em análise, pode assumir o sentido mais restrito de 'forma de governação' (ou seja 'regime, constituição').

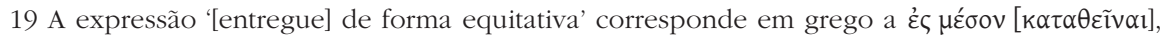
que significa à letra 'colocar no meio', posicionamento que implica que todos estão a igual distância do referente em causa (que aqui é: $\tau \dot{\alpha} \pi \rho \eta ́ \gamma \mu \alpha \tau \alpha$ ). 
ficastes a conhecer a do Mago. 3. Como pode a monarquia ser um regime 20 bem ordenado, se lhe é permitido fazer, sem nenhuma limitação, o que quiser? A verdade é que ela pode deixar fora do seu habitual juízo mesmo o melhor de todos os homens, quando empossado desse poder. Pois, ao passo que a insolência lhe nasce dos bens que possui, a inveja, por seu turno, é, desde sempre, inata ao género humano. 4. Como possui estes dois predicados, possui a vilania completa: comete muitos atos celerados, uns a fim de saciar a insolência, outros a inveja. No entanto o homem que é tirano não devia ser invejoso, uma vez que possui todos os bens! Torna-se, no entanto, no inverso disso mesmo, no relacionamento com os cidadãos: inveja os melhores (porque lhe são superiores e estão vivos), mas compraz-se com os mais vilões dos cidadãos, e é o melhor a acolher calúnias. 5. Eis, no entanto, o mais absurdo de tudo: se alguém o elogia de forma moderada, zanga-se, porque não é servido com desvelo; se o serve com desvelo, zanga-se com a bajulação. Vou mas é falar do que mais importa: subverte costumes pátrios, exerce violência contra mulheres e condena à morte sem julgamento. 6. A multidão, ao invés, quando governa, em primeiro lugar, tem o mais belo dos nomes - isonomia, em segundo, não faz nada do que faz o monarca! É por sorteio que exerce as magistraturas, presta contas pelo exercício de cada magistratura, toma todas as decisões em comum. Por isso proponho que nós, depois de renunciarmos a uma monarquia, promovamos o governo ${ }^{21}$ da multidão! É que é na maioria que reside o todo."

81. 1. Enquanto Otanes fazia esta proposta, Megabizo defendia que se virassem para uma oligarquia, argumentando o seguinte: "O que Otanes disse sobre abandonar a tirania também eu digo o mesmo; mas, quando exortava a que entregássemos à multidão o poder, desviou-se da melhor proposta! Efetivamente nada há de mais estúpido e insolente que uma

20 A palavra grega usada, $\chi \rho \tilde{\eta} \mu \alpha$, tem um sentido genérico muito idêntico ao de $\pi \rho \tilde{\eta} \gamma \mu \alpha$, pelo que, considero legítimo traduzi-la por 'regime', uma vez que a 'coisa, negócio' a que se refere, já ficou claro acima, é a 'coisa pública'.

21 Em grego só temos 'a multidão' ( $\tau$ ò $\pi \lambda \tilde{\eta} \theta$ os). No entanto no início deste mesmo parágrafo Heródoto usou uma expressão mais completa: 'a multidão governando' ( $\pi \lambda \tilde{\eta} \theta$ oc $\delta \dot{\varepsilon}$ ápxov), i. e. o 'governo da multidão'. Entendo, pois, que aqui estamos perante a mesma ideia, se bem que referida de forma sincopada. 
assembleia inútil. 2. Sem dúvida é absolutamente intolerável que homens que fogem da insolência de um tirano venham a cair na insolência de um povo indisciplinado. Ao menos aquele, se faz alguma coisa, fá-la com conhecimento, já a este não lhe assiste conhecimento algum! Como poderia, pois, ter conhecimento quem não foi ensinado, não sabe o que é belo, nem sabe nada por si próprio e, sem pensar, se atira à governação, semelhante a um rio de torrentes invernosas? 3. O povo, buscam-no, agora, aqueles que desejam mal aos Persas; mas nós, ao invés, escolhido um grupo de homens dos melhores, confiemos-lhe o poder! Realmente, entre esses, também nós estaremos incluídos e, por outro lado, é natural as melhores decisões surgirem dos melhores homens".

82. 1. Enquanto Megabizo fazia esta proposta, o terceiro a expor a sua proposta foi Dario, argumentando: "A mim, o que disse Megabizo a propósito de a multidão ter a governação ${ }^{22}$, parece-me ser uma argumentação correta; já o que disse sobre a oligarquia não é correto. Dos três regimes ${ }^{23}$ que temos à nossa disposição, afirmo que - apesar de todos eles serem os melhores (é o melhor o governo do povo, a oligarquia e a monarquia ) afirmo que este último é de longe superior aos outros. 2. De facto nada se se pode revelar melhor do que um só homem dotado de excelência! Ora bem, é porque se serve desse tipo de qualidades que pode zelar pela multidão de forma irrepreensível e guardar, no maior segredo, as suas decisões dos inimigos. 3. Na oligarquia é costume surgirem, entre o grande número de indivíduos que coloca o seu mérito ao serviço do interesse comum, poderosas rivalidades pessoais: de facto cada um deles, movido pelo desejo de liderar e de fazer vencer as suas propostas, leva a que apareçam, entre si e os outros, rivalidades insanáveis, das quais nascem dissensões, das dissensões homicídios e dos homicídios desemboca-se numa monarquia, e, com isto, torna-se evidente o quanto este é o melhor regime ${ }^{24}$.

22 Subentende-se 'governação' ( $\pi \rho \eta ́ \gamma \mu \alpha \tau \alpha)$, complemento direto do particípio. No original

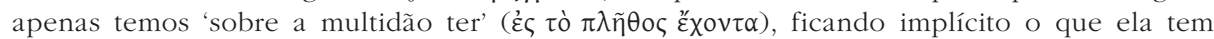
('a governação').

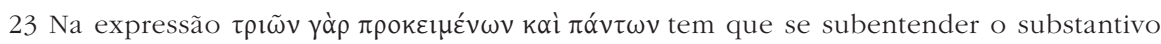
$\pi \rho \eta \gamma \mu \alpha ́ \tau \omega \nu$.

24 Uma vez mais o substantivo que se deve subentender é $\pi \rho \tilde{\eta} \gamma \mu \alpha$. 
4. Quando o povo governa, é inevitável o aparecimento da vilania! E quando a vilania se orienta para o interesse comum, o que surge entre os vilões não são rivalidades, mas sim poderosas alianças! A verdade é que os que cometem atos de vilania contra o interesse comum se encobrem mutuamente. Este é o tipo de situação que temos, até que alguém, assumindo a liderança do povo, detenha esses indivíduos! Graças a tais atos, ele é admirado pelo povo e é, certamente, por ser admirado que se torna um monarca! E com isto também ele prova que a monarquia é o melhor regime ${ }^{25}$. 5. Para resumir tudo o que foi aduzido num único termo: a liberdade donde nos veio e quem nos a deu? Do povo, da oligarquia ou de um monarca? Sou, por conseguinte, da opinião de que, visto nós termos sido libertados por um único homem, defendamos esse tipo de regime ${ }^{26}$ e, além disso, porque temos por bem não dissolver os costumes pátrios! Realmente essa não é a melhor atitude." 